\title{
Jenerasyon Y'nin Yatırım Aracı Tercihleri: Oyun Teorisi Yaklaşımı
}

\author{
Cihan Çiftçi*
}

İstanbul Üniversitesi, İktisat Fakültesi, İstanbul.

\begin{abstract}
$\ddot{O} z$
Yüksek satın alma gücü olan ve yakın zamanda pazarda baskm bir rol oynamaya başlayan Jenerasyon Y, Küresel Ekonomi 'de önemi giderek artmaktadır. İşletmelerin Jenerasyon $Y^{\prime}$ nin satın alma ve yatırım kararların etkileyemeye yönelik etkili stratejiler geliştirebilmesi için bu popülasyonun tüketim, harcama, birikim ve yatırım davranışlarının derinlemesine incelenmesi gerekmektedir. Türkiye'de Jenerasyon Y'nin birikim ve yatırm karar ve tercihlerini anlamaya yönelik yapılan araştırma oldukça sinırlıdır. Bundan dolayı bu araştırmada Türkiye'de ki Jenerasyon Y'nin yatırım tercihleri oyun teorisi ile tahmin edilmeye çalışılacaktır. Yapılan ilk oyun teorisinde üniversite öğrencilerinin yatırım tercihleri karşılaştırılmıştır, ikinci oyun teorisi ile de bu yatırım araçlarının öğrencilerinin beklentilerini ne ölçüde karşıladığı araştırılmıştır. Araştırmanın sonucunda Jenerasyon $Y^{\prime}$ nin en çok tercih ettiği yatırmm aracının altın olduğu ortaya çıkmıştır.
\end{abstract}

Anahtar Kelimeler: Jenerasyon Y, Yatırım Araçları, Oyun Teorisi Yaklaşımı

\section{Generation Y Investment Tool Preferences: Game Theory Approach}

\section{Abstract}

In the global economy, Generation $Y$ has a great importance since they are viewed as a generation with high buying power and expected to dominate the consumer market. For this reason, it is significant to analyze the consumption, spending, saving, and investment behavior of Generation Y; in order to develop effective strategies to influence not only their buying behavior but also their investment decisions. In Turkey, there is limited research on Generation Y's saving and investment decisions and preferences. Thus, the main purpose of this study is to predict Generation Y's investment preferences with the game theory. With the first game theory, this study compared the preference of investment tools among university students; and the second game theory was performed to measure whether these investment tools meet the profitability expectations of students. The findings of this study reveal that gold is the most preferred investment tool among Generation Y.

Keywords: Generation Y, Investment Tool, Game Theory Approach

\section{GİRIŞ}

Yatırım karar sürecine cinsiyet, gelir ve eğitim düzeyi gibi birçok demografik etmenler etki etmektedir (Hallahan vd., 2003:, Maxfield vd., 2010). Aynı zamanda kişilik özellikleri, değerler, duygular gibi karakteristik etmenlerde etki etmektedir (Mishra vd., 2010). Piyasaların ortamı, getiri oranları, beklenen risk düzeyleri gibi etmenler bireysel yatırım aracı tercihlerimiz üzerinde etkileri bulunmaktadır (Ferguson vd., 2011). Psikolojik ve sosyolojik faktörlerinde yatırım kararlarımızda etkili olduğu söylenmektedir (Chang, 2008). Yatırım aracı tercih sürecinde karar vericinin bilişsel yetenekleri, alışkanlıkları, değerleri, bilgisi ve olayları hızlı cevap vermeleri onların rasyonel kararlar almalarının önüne geçmektedir (Simon, 1987). Yatırımcıların kişisel özellikleri, önyargıları, geçmiş deneyimleri yatırım tercihleriyle ilişkili olduğu 
belirlenmiştir (Shiller, 2003; Sadi vd., 2011). Yatırımcının riske karşı tutumu ve piyasaya karşı algısı onun yatırım tercihini etkileyen en önemli faktördür (Young vd., 2012). Yatırımcıların riske karşı takındıkları tavırları onların yatırım aracı tercihine etki etmektedir (Bali vd., 2009). Yatırımcıların riske karşı takındıkları tutumları yaşla birlikte arttığı ve finansal okuryazarlık düzeyinin risk toleransını arttırdığı sonucuna varılmıştır (Grable, 2000). Yapılan bir diğer çalışmaya göre genç yatırımcıların yaşlı yatırımcılara göre daha fazla risk toleransına sahip olduğu sonucuna varılmıştır (Grable vd., 2004). Ayrıca finansal bilgileri de yatırım tercihinde önemli bir etken olmaktadir (Corter ve Chen, 2006).

Bu çalışmada ekonomide büyük bir güç haline gelen, kişisel özellikleri, gelir durumları, eğitim düzeyleri, risk tutumları gibi özellikler bakımından diğer kuşaklardan çok farklı olan Jenerasyon $Y$ kuşağının ileride tercih edeceği yatırım aracının belirlenmesinde oyun kuramı yaklaşımı kullanılmıştır. Yatırım aracı tercihinde birçok özelliğin etkili olduğu yapılan araştırmalar sonucunda elde edilmiştir. Yatırım aracı tercihinde Jenerasyon Y kuşağının dikkate aldığ önem derecelerine göre stratejiler belirlenmiş ve oyun kuramı yaklaşımı ile belirlenen stratejiler doğrultusunda hangi yatırım araçlarının gelecekte kazanç getireceği, yatırım araçlarının beklentilerine uzaklıkları, birbirlerine üstün oldukları ve denge durumundaki stratejiler belirlenerek bu kuşağın gelecekte tercih edeceği yatırım aracının tahminlemesi yapılmıştır.

\section{JENERASYON Y KUŞAĞI KİMDİR?}

Kuşaklar geçmişten günümüze yaş aralıklarına göre beş farklı grupta sınıflandırılmıştır. Gelenekselciler (1930-1945), Bebek Patlaması (1946-1964), X Kuşağı (1965-1976), Y Kuşağı (1977-1994), Z Kuşağ1 (1994 ve sonrası) şeklindedir (Williams ve Page, 2011). Dünyada yaygın olarak kullanılan kuşak tanımları ise, Sessiz Kuşak (Savaş Kuşağı - Silent Generation) (1927-1945), Büyük Bebek Patlaması (The Baby Boomers Generation) (1946-1965), X Kuşağı (Gen X - Baby Busters) (1965-1979), Y Kuşağı (Echo Boom - Millenials) (1979-1999), Z Kuşağı (Gen Z) (2000 ve sonrası) şeklinde sınıflandırılmıştır (Ayvaz, 2013).

Jenerasyon $Y$ kuşağı ismi kendinden önceki kuşak olan X kuşağından farklarını belirtmek için ilk kez 1993 yılında kullanılmıştır (Howe ve Strauss, 1992a). Daha sonra Jenerasyon Y kuşağı, millennials, generationnext, digitalgeneration, echoboomers ve nexters gibi isimlerde kullanılmıştır (Broadbridge vd., 2007). Jenerasyon Y kuşağı yaş aralığı farklı çalışmalarda birçok görüş ortaya atılmıştır. Bazı araştırmacılara göre 19772000 aralığında (Kotler ve Armstrong, 2010), 1977-1994 aralığında (Kim vd., 2009), 1980-2000 aralığında (Salahuddin, 2010; BucuȚ̆ A, 2015), 1978-2000 yaş aralığında (Broadbridge vd., 2007), 1982-2004 yaş aralığında (Howe ve Strauss, 1992b) sonuçlar elde edilmiştir. 


\section{JENERASYON Y KUŞAĞININ ÖZELLIKLERI}

Global İletişim Ajansı Edelman 8095, 1980 ile 1995 yılları arasında doğmuş Jenerasyon $\mathrm{Y}$ kuşağının olaylara bakış açılarını, marka tercihlerini ve markaların hayatlarındaki yerlerini, kültürel değişimleri gibi birçok konuda kapsamlı bir analiz sunmaktadır. Araştırmaya Türkiye dahil 11 ülkeden 4 bin kişi dahil olmuştur. Ajans direktörü Alex Abraham, 2025 yılı itibari ile çalışan nüfusun \%75'ini oluşturacak olan Jenerasyon $Y$ kuşağının en küçük üyesinin 18, en büyük üyesinin 33 yaşında olacağını, bugünün dünyasına yön vererek büyük bir harcama gücünü ellerinde bulunduracaklarını söylemiştir. Elde edilen araştırma raporlarına göre dünyadaki nüfuslarının 1,8 milyar olduğu, 2018 yılı itibariyle bir önceki kuşaktan daha fazla harcama hacmine sahip olacağı, ekonomik belirsizlik, internet, facebook, akıllı telefonlar hayatlarında büyük bir etki yarattığı, tarihteki en eğitimli ve en fazla çeşitlilik barındıran nesil olduğu, internet ve mobil teknolojilerine en hızlı adapte olan, \%74 'ünün satın alma eğilimlerinden yönlendirme güçlerinden dolayı diğer kuşakların kararlarını etkileyebileceklerini düşünmektedirler. Raporda elde edilen sonuçlara göre Jenerasyon Y kuşağının en büyük hedefi \%79'u kişisel tutkuları ile örtüşen bir iş yapmak, \%78'i ev sahibi olmak, \%72'si aile kurmak/evlenmek şeklinde sıralanmıştır. Türkiye'deki Jenerasyon Y kuşağının en büyük hedefleri arasında ise \%86'sı bir ev sahibi olmak, \%82'si iş yerinde güçlü bir unvan sahibi olmak, \%80'i yüksek maaşlı bir işte çalışmak şeklinde sıralanmıştır (Bugaoglu, 2013). Jenerasyon Y kuşağını yaptığı araştırmalar sonucunda 3 önemli özellikle karakteristik özelliklerini belirlemiştir. Bunlar, büyük ırk ve çeşitliliğe sahip olması, kişisel bağımsızlıklarına düşkün, para ve iş güvenliği konusunda daha iyimser olmaları şeklindedir (Halstead, 2006). Jenerasyon Y kuşağının karakteristik özellikleri; kendine güvenen, girişimci (Martin, 2005; Tolbize, 2008), açık fikirli, son derece bilgili, yetenekli ve işbirlikçi (Eisner, 2005), pozitif olan, enerjik ve yavaşlığ sevmeyen (Francis-Smith, 2004), dikkatli bir yatırımcı olup mali açıdan güçlü olan (Foreman, 2006), kariyerine çok düşkün olan ve iş yaşamını kariyerine feda edebilecek özelliklere sahiptir (Broadbridge vd., 2007). Jenerasyon Y kuşağının istihdam özellikleri; kendi işine sahip olmayı tercih eden ve istihdam esnekliği isteyen (Martin, 2005; Mitchell, 2005; McEwan, 2009), işverenlerin yüksek beklentisi olan (Foreman, 2006), başarı odaklı ve iyi bir çalışma ortamı isteyen, meslek gelişimini profesyonel düzeyde geliştiren (Eisner, 2005: 4), adil tazminat isteyen (Morton, 2002), kariyerleri için bireysel sorumluluk alan, bilgiyi kullanma derecesi yüksek ve hızlı takip yeteneği gelişmiş olan (Broadbridge vd., 2007). Jenerasyon $Y$ kuşağının yönetim yaklaşımları ve durum özellikleri; rahat ve tek başına çalışmayı seven, özgürlük ve esneklik isteyen, yönetsel destek isteyen (Martin, 2005), aynı görevler üzerinde çalışma ve paylaşılan değerlere önem verme, alınacak kararlara katkıda bulunma (Eisner, 2005), yetkili olmayı seven, pozitif bir şirket ve patron kültürünü benimseyen (Morton, 2002), arzularına anında geri bildirim verilmesini isteyen özelliklere sahiptir (Francis-Smith, 2004). Jenerasyon Y kuşağının kariyer gelişim özellikleri; zorlu işleri seven (Martin, 2005), kendini geliştirmeyi ve yetiştirmeyi önemseyen, eğitim olanakları ile mesleki gelişimlerini geliştirmek isteyen, başarılı olma ihtiyacı olan, kişisel hedeflerine ulaşma arzusu olan (Eisner, 2005), kariyerleri için 
başarılı ve güvenilir olan (Broadbridge vd., 2007), değişikliği benimseyen ve hedef odaklı özelliklere sahiptir (Foreman, 2006). Jenerasyon Y kuşağının kişisel değer özellikleri; dengeli bir yaşam tarzı olan, çeşitliliği seven, hoşgörülü olan (Morton, 2002), ailevi değerlere önem veren, iş-yaşam dengesi olan, adalet değeri ve ahlak duygusu güçlü olan, gönüllü bir fark yaratma çabası olan, anlamlı işler yapan, özgürlük için savaşan, sosyal bilinci yüksek olan özelliklere sahiptir (Eisner, 2005).

\section{JENERASYON Y KUŞAĞI YATIRIM DAVRANIŞLARI}

Jenerasyon $\mathrm{Y}$ kuşağı tarihte elinde en fazla para bulunduran bir kuşaktır (Kennedy, 2001). Dolaysıyla bu kuşak ekonomide en büyük tüketici grubunu oluşturur. Jenerasyon $Y$ kuşağının büyüklüğü ve tüketim gücü nedeniyle daima araştırma konusu olmuştur (Branchik, 2010). MFS raporlarına göre 2011 yllında yapılan 18-30 yaş aralığındaki Amerika'daki Jenerasyon $Y$ kuşağının yatırım davranışlarına ilişkin yapılan bir araştırma sonucuna göre \% 40'nın borsa yatırımın kendilerini rahat hissettirmeyeceği, \%54'ünün tercih edeceği tüm yatırım seçeneklerinden bunalmış olduğunu, \%30'nun birincil yatırım amaçlarının paralarını korumak olduğu, diğer yaş gruplarına oranla hisse senedi yatırımına \%30 daha fazla para ayırdığı, genel olarak da yatırım hakkında endişeli oldukları sonucuna varılmıştır (MFS, 2011). Yatırım Şirketi Enstitüsü (ICI) 2010 yılı verilerine göre Jenerasyon Y kuşağı yatırımcılarının geçmiş yıllara göre hisse senedi sahibi olmaları giderek azalan bir trend izlemektedir. Bu sonuçtan yararlanarak $\mathrm{X}$ kuşağının ortalama risk alma eğilimleri, Jenerasyon $\mathrm{Y}$ kuşağı yatırımcılarına göre daha fazla olduğu sonucuna varılmıştır. Jenerasyon $\mathrm{Y}$ kuşağı yatırımcıların finansal risk alma düzeyleri, \%7 oranında önemli bir kazanç elde etmek için önemli bir risk, \%25 ortalamanın üstünde kazanç için ortalamanın üstünde risk, \%48 oranında ortalama kazanç oranında ortalama risk, \%11 oranında ortalamanın altında kazanç için ortalamanın altında risk, $\% 9$ oranında herhangi bir risk almak istemeyen oranlar oluşturmuştur (John, 2011). Genç nesillerin yatırım davranışlarını anlamaya yönelik yapılan çalışmada, anket veriler kullanılarak bilgi, tecrübe ve gelir, yatırım fonları genç kuşakların yatırım davranışlarını farklılaştıran en önemli etkenler olduğu belirlenmiştir. Ayrıca cinsiyetinde yatırım davranışlarının farklılaştırılmasında önemli bir faktör olduğu görülmüştür (Wang, 2011). Jenerasyon Y kuşağının yatırım yapmadan önce dikkate aldığı faktörler \% 68,7 yatırım araçlarının güvenirliği, \% 61,2 yüksek faiz oranı, \% 53,5 düşük risk oranı şeklinde sıralanmıştır (Ganesan, 2012). Tüketim ve harcamayı bu kadar çok seven, eline geçen para diğer kuşaklara göre çok daha fazla olan Jenerasyon Y kuşağının, eline geçen parayı gelecekte nasıl değerlendireceği ve hangi yatırım araçlarını kullanacağının önemi de gün geçtikçe merak konusu olmaktadır. Jenerasyon Y kuşağ1 tüketicileri küresel pazarda ekonomi üzerinde çok büyük bir etkiye sahip önemli bir güç olarak karşımıza çıkmaktadır. Bu grubun potansiyeline rağmen orta yaşlı üyeleri olan üniversiteli $Y$ kuşağının son derece açgözlü oldukları ve bu bireylerin tercih ve tüketim davranışlarının bilinmediği söylenmektedir. Bu nedenle $Y$ kuşağ özel neslin benzersiz güç ve çekiciliği üniversite öğrencileri ile birleştiğinde üniversite pazarının önemi daha anlamlı olacaktır (Noble vd., 2009). 


\section{OYUN KURAMI YAKLAŞIMI}

Elde edilen kazançlar veya kayıpların durumlarına göre oyun ikiye ayrılır. Bunlar sifır toplamlı oyun ile sifır toplamlı olmayan oyunlardır. Sıfır toplamlı oyunlarda kazanç ve kayıpların toplamının sıfır olduğu oyun durumlarıdır. Bir oyuncunun kazandığı kazanç, diğer oyuncunun kaybettiği duruma eşittir (Winston ve Goldberg, 2004). Bu oyunlarda kişi sayısına göre de sınıflandırmalar yapılmaktadır. İki kişilik sıfır toplamlı oyun da oyuncuların rekabet içinde oldukları, çıkarların çatıştığ ve en yaygın oyun türüdür. Bu oyunda kayıp ve kazançlar bir matriste gösterildiği için bu oyuna matris oyunu denir (Peters, 2015). Oyunların tamamı bir oyuncunun kazandığı, diğer oyuncunun kaybettiği durumlardan oluşmamaktadır. Öyle stratejiler vardır ki her iki oyuncunun kazandığı durumlar olabilir. Böyle oyunlara iki kişilik sıfır toplamlı olmayan oyunlar denir. Sıfır toplamlı olmayan oyunlarda her iki oyuncu içinde baskın olan strateji dengesi bulunur. Bir oyuncunun seçtiği bir strateji, diğer oyuncunun seçtiği her stratejiden daha kazançlı bir durumda ise burada baskın strateji vardır. Baskın stratejiler oyuncular arasındaki baskınlığı tam olarak belirleyemiyorsa, Nash dengesi bulunmaya çalışılır. Nash dengesi her iki oyuncu için kazanç durumudur. Her oyuncu rakibinin stratejilerini en iyi şekilde tahmin edebildiği ve stratejilere en iyi şekilde tepki verebildikleri optimal denge durumudur (Nash, 1951). Oyunun değeri, oyun sonunda oyuncular tarafından ödenen miktar olup, oyunun maksimum değeri satır değerlerinin en büyük değerlerinden en küçük olanı ile oyunun minimum değeri ise sütunların en küçük değerlerinden en büyük olan değerler arasındadır. Oyunun maksimin ve minimaks değerlerinin eşit olduğu noktaya oyunun tepe noktasıdır. Oyunun tepe noktası olan oyunlar denge durumundadır. Bu denge noktasında her iki oyuncu için en kazançlı olduğu durumdur.

$\mathrm{Bu}$ çalışmada sıfır toplamlı ve sıfır toplamlı olmayan iki oyun problemi kurulmuştur. Birinci oyun problemlerinde sıfır toplamlı oyun, ikinci oyun problemlerinde sıfır toplamlı olmayan oyun modelleri kurulmuştur. Oyuncular altın, gayrimenkul ve döviz yatırım araçlarıdır. Stratejiler ise, faiz oranının yüksek olması, güvenilir olması, yüksek kar getirisinin olması, yatırım aracı ile ilgili bilgi sahibi olunmasi.

\section{METEDOLOJI VE BULGULAR}

Jenerasyon $Y$ kuşağ1 İstanbul Üniversitesi İktisat Fakültesi üniversite öğrencilerinin gelecekte hangi tür yatırım aracını tercih edeceklerini belirlemek amacıyla 2016 yılında anket çalışması yapılmıştır. İstanbul Üniversitesi İktisat Fakültesinde yaklaşık 10.000 kişilik öğrenciden rastgele örneklem yöntemi kullanılarak 668 öğrenciye ulaşılmıştır. Anket uygulanan örnek grubun \%5 hata payı ve \%99 güvenirlikle yeterli olduğu ve ana kütleyi anlamlı bir şekilde temsil ettiği hesaplanmıştır. Elde edilen sonuçlara göre araştırmaya katılan 668 öğrencinin \%58,6'u kadın, \%41,4'i erkek öğrencilerden oluşmaktadır. \%82,1'si örgün öğretimde, \%17,9'u uzaktan öğretimden oluşmaktadır. Öğrencilerin, \%65,3'si çalışmıyor, \%11,2'i geçici işlerde, \%13,7'ü yarı-zamanlı işlerde, \%9,9'i tam-zamanlı işlerde çalışmaktadır. $\% 60,5^{\prime}$ nın düzenli bir gelir kaynağı olduğunu söylüyorken, \%39,5'nın ise düzenli bir 
gelir kaynağının olmadığını belirtmiştir. \%28,9’u para birikimlerini düzenli olarak gerçekleştiremezken, \%71,1'i para birikimini düzenli olarak geçekleştirmektedir. Öğrencilerin \%58'si gayrimenkul yatırımı, \%47,8'i altını, \%41,9 dövizi, \%25,1'u hisse senedini yatırım aracı olarak kullanmayı düşünmektedir. \%20,9'u parasının çeyreğini biriktirirken, \%9,6'sı yarısını biriktirmekte, \%21,1'i ise parasının tamamını harcamakta birikim yapmamaktadır. Çalışmada Jenerasyon Y kuşağının gelecekte en çok tercih etmeyi düşündükleri iki yatırım aracı ele alınarak iki ayrı oyun problemi kurulmuştur. Birinci oyun problemi, öğrencilerin tercih ettikleri yatırım araçlarının birbirlerine göre durumlarını ifade eden sıfır toplamlı oyun yaklaşımıdır.

Tablo 1. Oyun Teorisi Stratejileri

\begin{tabular}{|l|l|}
\hline 1 & Faiz Oranının Yüksek Olması \\
\hline 2 & Yüksek Kar Getirisi Olacağının Düşünülmesi \\
\hline 3 & Güvenli Olduğunun Düşünülmesi \\
\hline 4 & Yatırım Araçları ile İlgili Bilgi Sahibi Olunması \\
\hline
\end{tabular}

İkinci oyun problemi ise, her iki yatırım aracının öğrencilerin gelecekte yatırım araçlarından beklentilerini ne ölçüde karşıladığını çözümleyen sıfır toplamlı olmayan oyun yaklaşımıdır. Çalışma kapsamında hazırlanan anket ile toplanan verilerden oyuncular ve her iki oyun matrisleri oluşturulmuştur. Jenerasyon $\mathrm{Y}$ kuşağının gelecekte tercih edecekleri yatırım araçlarının belirlenmesinde göz önünde bulundurdukları olası ölçütler ve bu ölçütlere ne derece önem verdiklerini de anket yardımıyla öğrencilerden istenmiştir. Gelecekte tercih edecekleri yatırım araçlarını belirlerken kullanacakları ölçütler Tablo 1'de verilmiştir. Ankette kullanılan ölçütler 7'li likert ölçeğine göre Cronbach Alpha güvenirlik analizi yapılmıştır. Elde edilen sonuca göre Tablo 2'de ölçütlerin Cronbach Alpha katsayısının 0,681 elde edilmiş olup güvenilir olduğu sonucuna varılmıştır.

Tablo 2. Stratejilerin güvenirlik analizi

\begin{tabular}{|c|c|c|c|c|}
\hline & Ölçüt & $\begin{array}{l}\pi \\
\hat{0} \\
0 \\
0 \\
0 \\
0 \\
0 \\
0 \\
\vdots \\
\Xi\end{array}$ & 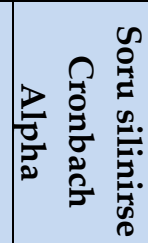 & 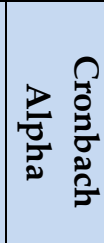 \\
\hline 1 & Faiz Oranının Yüksek Olması & 407 & 687 & \multirow{4}{*}{0,681} \\
\hline 2 & Yüksek Kar Getirisi Olacağının Düşünülmesi & 615 &, 509 & \\
\hline 3 & Güvenli Olduğunun Düşünülmesi & 427 & 645 & \\
\hline 4 & Yatırım Araçları ile İlgili Bilgi Sahibi Olunması & 475 & ,615 & \\
\hline
\end{tabular}

Tablo 3'teki ölçeklere ait istatistik veri değerlere göre, 688 anketten kayıp verinin olmadığı görülmektedir. Ölçeklerin ortalama değerleri arasında 6,1235 değeriyle yatırım aracının güvenli olduğu ölçeğine aittir. Standart sapması 1,43084 değeri ile en az sapma yatırım aracının güvenli olduğu ölçeğine aittir. Basıklık ve çarpıklık değerlerine göre yatırım araçlarının güvenli olduğu ölçeğinin normal dağılım göstermediği, diğer ölçeklerin normal dağılım özelliğine sahip olduğu gözlenmektedir. 
Tablo 3. Stratejilere ait istatistiki veriler

\begin{tabular}{|l|c|c|c|c|}
\hline \multicolumn{1}{|c|}{ Ölçekler } & $\begin{array}{c}\text { Faiz oranı } \\
\text { yüksek }\end{array}$ & $\begin{array}{c}\text { Yüksek kar } \\
\text { getirisi }\end{array}$ & $\begin{array}{c}\text { Güvenli } \\
\text { olduğu }\end{array}$ & $\begin{array}{c}\text { Bilgi sahibi } \\
\text { olunması }\end{array}$ \\
\hline Geçerli değer & 688 & 688 & 688 & 688 \\
\hline Kayıp değer & 0 & 0 & 0 & 0 \\
\hline Ortalama & 4,2573 & 5,4593 & 6,1235 & 5,8663 \\
\hline St.sapma & 2,32932 & 1,87951 & 1,43084 & 1,55243 \\
\hline Varyans & 5,426 & 3,533 & 2,047 & 2,410 \\
\hline Skewness &,- 237 & $-1,126$ & $-1,887$ & $-1,422$ \\
\hline Kurtosis & $-1,418$ &, 226 & 3,306 & 1,430 \\
\hline
\end{tabular}

Tablo 4'te uygulanan likert ölçeği sonucunda Jenerasyon Y kuşağ öğrencilerinin yatırım araçlarını tercih ederken ölçeklere verilen puanlar yer almaktadır. Yatırım aracının faiz oranın yüksek olması ölçeğine $\% 28,3$ değeriyle kesinlikle katılıyorum, yüksek kar getirisine sahip olması \%45,2 değeriyle kesinlikle katılıyorum, güvenli olması ölçeğine $\% 62,2$ değeriyle kesinlikle katılıyorum ve $\% 53,3$ değeriyle yatırım aracı hakkında bilgi sahibi olunmasına kesinlikle katılıyorum cevapları verilmiştir. Jenerasyon $\mathrm{Y}$ kuşağının gelecekte yatırım aracı tercihinde en önemli gördüğü ölçeğin yatırım aracının güvenli olmasını istemektedir. Şekil 2'de Jenerasyon $Y$ kuşağı öğrencilerinin gelecekte tercih edecekleri yatırım araçlarının tercih edilme sayıları verilmiştir.

Tablo 4. Stratejilere ait likert ölçek puanları

\begin{tabular}{|c|l|c|c|c|c|c|c|c|c|}
\hline \multicolumn{2}{|c|}{ Ölçekler } & $\begin{array}{c}\text { Faiz } \\
\text { oranı } \\
\text { yüksek }\end{array}$ & Yüzde & $\begin{array}{c}\text { Yüksek } \\
\text { kar } \\
\text { getirisi }\end{array}$ & Yüzde & $\begin{array}{c}\text { Güvenli } \\
\text { olduğu }\end{array}$ & Yüzde & $\begin{array}{c}\text { Bilgi } \\
\text { sahibi } \\
\text { olunması }\end{array}$ & Yüzde \\
\hline \multirow{4}{*}{$\begin{array}{c}\text { Likert } \\
\text { Ölçek } \\
\text { Değerleri }\end{array}$} & 1,00 & 176 & 25,6 & 57 & 8,3 & 20 & 2,9 & 22 & 3,2 \\
\cline { 2 - 11 } & 2,00 & 19 & 2,8 & 12 & 1,7 & 6 &, 9 & 8 & 1,2 \\
\cline { 2 - 11 } & 4,00 & 47 & 6,8 & 31 & 4,5 & 11 & 1,6 & 30 & 4,4 \\
\cline { 2 - 11 } & 5,00 & 99 & 14,4 & 82 & 11,9 & 54 & 7,8 & 63 & 9,2 \\
\cline { 2 - 11 } & 6,00 & 53 & 14,4 & 93 & 13,5 & 78 & 11,3 & 101 & 14,7 \\
\cline { 2 - 11 } & 7,00 & 195 & 28,3 & 311 & 45,2 & 428 & 62,2 & 367 & 53,3 \\
\cline { 2 - 11 } & Total & 688 & 100,0 & 688 & 100,0 & 688 & 100,0 & 688 & 100,0 \\
\hline
\end{tabular}

Anketi yanıtlayan 688 Jenerasyon $\mathrm{Y}$ kuşağı üniversite öğrencisinden, gelecekte tercih edeceği yatırım araçlarından birden fazla seçim yaparak cevapları alınmıştır. Elde edilen Tablo 3'deki sonuçlara göre altın 328, gayrimenkul 396, döviz 287, hisse senetleri 172, vadeli tl mevduatı 154, vadeli döviz mevduatı 96, usd tahvil 89, euro tahvil 86 , devlet tahvili 80 , diğer 66 , hazine bonosu 54 , banka bonoları 49 , finansman bonoları 47, repo 11 öğrenci tarafından gelecekte kullanmayı düşündüğü yatırım aracı olarak tercih etmişlerdir. Böylece daha yüksek oranda tercih edilen altın ve gayrimenkul yatırım araçlarından, altının birinci oyuncu ve rakibi olarak gayrimenkul yarımın ikinci oyuncu olarak belirlenmiştir. 


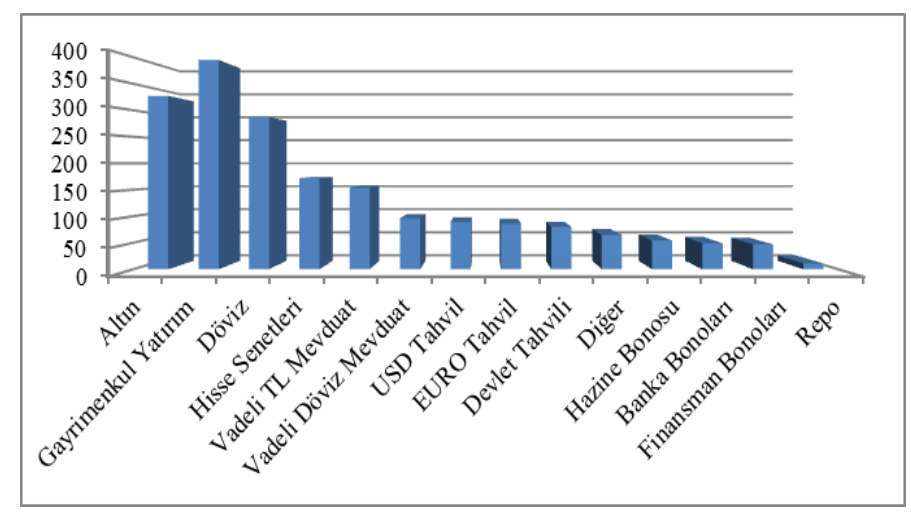

Şekil 1. Tercih Edilen Yatırım Araçları

Oyun probleminde amaç Jenerasyon $\mathrm{Y}$ kuşağı iktisat fakültesi üniversite öğrencilerinin gelecekte hangi yatırım aracını tercih edeceği ve tercih ettiği yatırım aracının hangi ölçütlere göre tercih ettiğinin belirlenmesine yöneliktir. Belirlenen stratejiler, belirlenen ölçütlere karşılık gelecektir. Gelecekte tercih edeceği yatırım aracının tercih etme ölçütleri oyun probleminin stratejileri olacaktır. İki oyuncunun belirlenen stratejiler göre birbirlerine göre durumları analiz edilecektir. Belirlenen ölçütler 7'li likert ölçeğine göre öğrencilerden tercih etme dereceleri istenmiştir. Öğrencilerin altın ve gayrimenkul yatırım araçlarını belirlenen ölçütlere göre değerlendirme puanları hesaplanmıştır.

Birinci oyun problemi olarak sıfır toplamlı oyunla elde edilen ölçütlerin değerlendirme puanlarına göre birbirlerine karşı durumları değerlendirilecektir. İkinci oyun problemi olarak sıfır toplamlı olmayan oyun ile oyuncuların birbirlerine göre kayıp-kazanç durumları değerlendirilecektir. Oyunlarda kullanılacak stratejiler ise, faiz oranının yüksek olması, yüksek kar getirisi olacağının düşünülmesi, güvenli olduğunun düşünülmesi, yatırım araçları ile ilgili bilgi sahibi olunması şeklinde belirlenmiştir.

Birinci oyun olan sıfır toplamlı oyunda öğrencilerin ölçütlere verdikleri puanlar toplanarak oyun matrisleri oluşturulmuştur. Puanlar oranlara dönüştürülerek tercih edilen yatırım aracının ölçütleri karşılama yüzdeleri elde edilmiştir. Tablo 5'te her oyuncunun ölçütlere göre göre aldığı değerleri verilmiştir.

Tablo 5. Strateji İçin Oyuncuların Aldıkları Puanlar

\begin{tabular}{|l|c|c|l|c|c|}
\hline \multicolumn{3}{|c|}{ Altın } & \multicolumn{3}{c|}{ Gayrimenkul yatırım } \\
\hline \multicolumn{1}{|c|}{ Stratejiler } & Puan & Yüzde & Stratejiler & Puan & Yüzde \\
\hline Faiz oranı yüksek & 1268 & 0,1802 & Faiz oranı yüksek & 1734 & 0,1974 \\
\hline Yüksek kar getirisi & 1767 & 0,2511 & Yüksek kar getirisi & 2238 & 0,2548 \\
\hline Güvenli olduğu & 2056 & 0,2922 & Güvenli olduğu & 2463 & 0,2805 \\
\hline Bilgi sahibi olunması & 1945 & 0,2764 & Bilgi sahibi olunması & 2347 & 0,2673 \\
\hline Toplam & 7036 & 1,0000 & Toplam & 8782 & 1,0000 \\
\hline
\end{tabular}

Altın birinci oyuncu olarak düşünülmüş ve gayrimenkul yatırımın aldığı puanlar birinci oyuncunun aldığı puana göre değerlendirilecektir. Birinci oyuncunun 
aldığı puanlar, ikinci oyuncunun aldığı puanlardan çıkartılarak sıfır toplamlı oyun matrisi Tablo 6' da elde edilmiştir.

Tablo 6. Sifır Toplamlı Oyun Matrisi

\begin{tabular}{|r|l|c|c|c|c|}
\hline \multirow{2}{*}{ OYUN 1 } & \multicolumn{5}{|c|}{ Gayrimenkul yatım (İkinci Oyuncu) } \\
\cline { 2 - 7 } & Stratejiler & $\begin{array}{c}\text { Faiz } \\
\text { oranı } \\
\text { yüksek }\end{array}$ & $\begin{array}{c}\text { Yüksek } \\
\text { kar } \\
\text { getirisi }\end{array}$ & $\begin{array}{c}\text { Güvenli } \\
\text { olduğu }\end{array}$ & $\begin{array}{c}\text { Bilgi } \\
\text { sahibi } \\
\text { olunması }\end{array}$ \\
\hline \multirow{2}{*}{$\approx$} & Faiz oranı yüksek & $-0,0172$ & $-0,0746$ & $-0,1002$ & $-0,0870$ \\
\cline { 2 - 7 } & Yüksek kar getirisi & 0,0537 & $-0,0037$ & $-0,0293$ & $-0,0161$ \\
\cline { 2 - 7 } & Güvenli olduğu & 0,0948 & 0,0374 & 0,0118 & 0,0250 \\
\cline { 2 - 7 } & Bilgi sahibi olunmasi & 0,0790 & 0,0216 & $-0,0040$ & 0,0092 \\
\hline
\end{tabular}

Altının faiz oranı yüksek stratejisinden aldığı puan, gayrimenkul yatırım aracının faiz oranı yüksek stratejisinden aldığı puana göre 0,0172 daha düşüktür. Altının faiz oranı yüksek stratejisinden aldığı puan, gayrimenkul yatırım aracının sırasıyla, yüksek kar getirisi stratejisinden aldığı puana göre 0,0746 , güvenli olduğu stratejisinden aldığı puana göre 0,1002, bilgi sahibi olunması stratejisinden aldığ 1 puana göre 0,0870, daha düşüktür. Bu sonuçlara göre faiz oranı yüksek stratejisine göre gayrimenkul yatırım altından daha kazançlıdır. Tablo 5'daki değerler altının her strateji için gayrimenkul yatırıma göre durumunu göstermektedir. Dolaysıyla negatif değerlerde gayrimenkul yatırımın altına göre daha kazançlı olduğu durumları göstermektedir. Birinci oyun da sıfır toplamlı oyun matrisini çözmek için, satırların en büyük ve sütunların en küçük değerine bakılır. Tablo 7 ' de satırların en büyük değerleri arasında en küçük 0,0118, sütunların en küçük değerleri arasından en büyük değer yine 0,0118 elde edilmiştir. Birinci oyunun değeri de 0,0118 olarak bulundu. Sonuç olarak, altın yatırım aracının güvenli olduğu stratejisi, gayrimenkul yatırım aracının her stratejisinden daha kazançlıdır. Jenerasyon Y kuşağının altın yatırım aracını, gayrimenkul yatırım aracına göre daha güvenilir bir yatırım aracı olarak görmektedir.

Tablo 7. Sıfır Toplamlı Oyunun Çözümü

\begin{tabular}{|c|c|c|c|c|c|c|}
\hline \multirow{2}{*}{ OYUN 1} & \multicolumn{5}{|c|}{ Gayrimenkul yatırım (İkinci Oyuncu) } & \multirow[b]{2}{*}{ Min } \\
\hline & Stratejiler & Faiz oranı yüksek & Yüksek kar getirisi & Güvenli olduğu & Bilgi sahibi olunması & \\
\hline \multirow{5}{*}{ 全 } & Faiz oranı yüksek & $-0,0172$ & $-0,0746$ & $-0,1002$ & $-0,0870$ & $-0,1002$ \\
\hline & Yüksek kar getirisi & 0,0537 & $-0,0037$ & $-0,0293$ & $-0,0161$ & $-0,0293$ \\
\hline & Güvenli olduğu & 0,0948 & 0,0374 & $\underline{0,0118}$ & 0,0250 & $\underline{0,0118}$ \\
\hline & Bilgi sahibi olunması & 0,0790 & 0,0216 & $-0,0040$ & 0,0092 & $-0,0040$ \\
\hline & Max & 0,0948 & 0,0374 & $\underline{0,0118}$ & 0,0250 & \\
\hline
\end{tabular}

İkinci oyun probleminde ise, Jenerasyon $\mathrm{Y}$ kuşağı öğrencilerinin gelecekte tercih edeceği yatırım aracını belirlerken dikkate aldıkları ölçütleri ne derece karşıladığı belirlenmiştir. Altın ve gayrimenkul yatırım araçlarının tercihinde dikkat edilen ölçütler bakımından stratejilerin puanları Tablo 8'de verilmiştir. 
Tablo 8. Önceliklerin Karşılaştırılması

\begin{tabular}{|l|c|c|c|c|c|c|c|c|}
\hline \multicolumn{2}{|c|}{ Altın } & \multicolumn{3}{c|}{ Gayrimenkul yatırım } & \multicolumn{3}{c|}{ Öncelikler } \\
\hline \multicolumn{1}{|c|}{ Stratejiler } & Puan & Yüzde & Stratejiler & Puan & Yüzde & Stratejiler & Puan & Yüzde \\
\hline Faiz oranı yüksek & 1268 & 0,1802 & Faiz oranı yüksek & 1734 & 0,1974 & Faiz oranı yüksek & 3002 & 0,1898 \\
\hline Yüksek kar getirisi & 1767 & 0,2511 & Yüksek kar getirisi & 2238 & 0,2548 & Yüksek kar getirisi & 4005 & 0,2532 \\
\hline Güvenli olduğu & 2056 & 0,2922 & Güvenli olduğu & 2463 & 0,2805 & Güvenli olduğu & 4519 & 0,2857 \\
\hline Bilgi sahibi olunması & 1945 & 0,2764 & Bilgi sahibi olunması & 2347 & 0,2673 & Bilgi sahibi olunmasi & 4292 & 0,2713 \\
\hline Toplam & 7036 & 1,0000 & Toplam & 8782 & 1,0000 & Toplam & 15818 & 1,0000 \\
\hline
\end{tabular}

İkinci oyun problemi sıfır toplamlı olmayan oyunda, yatırım araçlarının ölçütlere ne derece yakın oldukları ölçülmüştür. Birinci oyuncu olarak altın yatırım aracı belirlenmiştir. Jenerasyon $\mathrm{Y}$ kuşağının altın ve gayrimenkul yatırım araçlarına verdikleri puanların, genel olarak yatırım aracı tercihinde öğrencilerin öncelikleri, belirlenen stratejiler bazında karşılaştırılmıştır. Altın ve gayrimenkul yatırım araçlarını tercih eden öğrencilerin stratejilere verdikleri puan yüzdelerinin, genel öğrencilerin yatırım aracı tercihinde stratejilere verdikleri puanların farkları alınmıştır.

Altın yatırım aracının, Jenerasyon $Y$ kuşağı öğrencilerinin önceliklerine göre belirlenen stratejilere uzaklıkları Tablo 9'da verilmiştir. Altın yatırım aracını tercih eden öğrencilerinin güvenli olduğu stratejisine verdikleri puanın, hedef kitlenin faiz oranı yüksek, yüksek kar getirisi ve bilgi sahibi olunması stratejilerine verdikleri puanlardan daha yüksek çıkmıştır.

Tablo 9. Altın Yatırım Aracının Beklentilere Uzaklık Matrisi

\begin{tabular}{|l|c|c|c|c|}
\hline \multicolumn{5}{|c|}{ Altın } \\
\hline \multicolumn{1}{|c|}{ Stratejiler } & Faiz oranı yüksek & Yüksek kar getirisi & Güvenli olduğu & Bilgi sahibi olunması \\
\hline Faiz oranı yüksek & $-0,0096$ & $-0,0730$ & $-0,1055$ & $-0,0911$ \\
\hline Yüksek kar getirisi & 0,0614 & $-0,0021$ & $-0,0346$ & $-0,0202$ \\
\hline Güvenli olduğu & 0,1024 & 0,0390 & 0,0065 & 0,0209 \\
\hline Bilgi sahibi olunması & 0,0867 & 0,0232 & $-0,0093$ & 0,0051 \\
\hline
\end{tabular}

Gayrimenkul yatırım aracının, Jenerasyon Y kuşağı öğrencilerinin önceliklerine göre belirlenen stratejilere uzaklıkları Tablo 10'da verilmiştir. Gayrimenkul yatırım aracını tercih eden öğrencilerinin faiz oranı yüksek stratejisine verdikleri puanın, hedef kitlenin güvenli olduğu, yüksek kar getirisi ve bilgi sahibi olunması stratejilerine verdikleri puanlardan daha düşük çıkmıştır.

Tablo 10. Gayrimenkul Yatırım Aracının Beklentilere Uzaklık Matrisi

\begin{tabular}{|l|c|c|c|c|}
\hline \multicolumn{5}{|c|}{ Gayrimenkul yatırım } \\
\hline \multicolumn{1}{|c|}{ Stratejiler } & Faiz oranı yüksek & Yüksek kar getirisi & Güvenli olduğu & Bilgi sahibi olunması \\
\hline Faiz oranı yüksek & 0,0077 & $-0,0557$ & $-0,0882$ & $-0,0739$ \\
\hline Yüksek kar getirisi & 0,0651 & 0,0016 & $-0,0308$ & $-0,0165$ \\
\hline Güvenli olduğu & 0,0907 & 0,0273 & $-0,0052$ & 0,0091 \\
\hline Bilgi sahibi olunması & 0,0775 & 0,0141 & $-0,0184$ & $-0,0041$ \\
\hline
\end{tabular}

Elde edilen sonuçlara göre hedef kitlenin stratejilere verdikleri puanlar ile altın ve gayrimenkul yatırım araçlarına verilen puanlar arasındaki farkın küçük olması ilgili stratejinin beklentilere yakın olduğu, büyük olması beklentilerden uzakta olduğu, 
negatif olması ise beklentilerin altında olduğunu göstermektedir. Altın yatırım aracını seçen öğrencilerin faiz oranı yüksek stratejisine verdikleri puan 0,1802 iken, Jenerasyon Y kuşağının faiz oranı yüksek stratejisine verdikleri önem derecesinin 0,1898 olarak elde edilmiştir. Elde edilen uzaklık değeri $-0,0096$ ve negatif değer bulunmuştur. Dolaysıyla altın yatırım aracının faiz oranı yüksek stratejisi bakımından beklentilerin altında kalmıştır.

Oyuncuların stratejiler bazında beklentilere uzaklıklar matrislerindeki değerleri 100 ile çarpılarak sıfırdan büyük değerlerin kazançları, sıfırdan küçük değerlerin ise kayıpları olarak değerlendirilecektir. Sıfır toplamlı olmayan oyunun matrisi ise, oyunun dengesini belirlemek için baskın stratejiler aranacaktır. Baskın strateji dengesi aynı zamanda oyunun Nash dengesidir. Dolaysiyla bu belirlenen Nash denge stratejisi her iki oyuncu içinde kazançlı strateji olarak kabul edilir. Nash dengesi Tablo 11'de $(10,25 ; 9,07)$ olarak elde edilmiştir.

Tablo 11. Altın ve Gayrimenkul Nash Dengesi

\begin{tabular}{|c|c|c|c|c|c|}
\hline \multirow{2}{*}{ OYUN 2} & \multicolumn{5}{|c|}{ Gayrimenkul yatırım (İkinci Oyuncu) } \\
\hline & Stratejiler & Faiz oranı yüksek & Yüksek kar getirisi & Güvenli olduğu & Bilgi sahibi olunması \\
\hline \multirow{4}{*}{ 先至 } & Faiz oranı yüksek & $(-0,96 ; 0,77)$ & $(-7,30 ;-5,58)$ & $(-10,54 ;-8,82)$ & $(-9,11 ;-7,39)$ \\
\hline & Yüksek kar getirisi & $(6,14 ; 6,50)$ & $(-0,20 ; 0,16)$ & $(-3,46 ;-3,08)$ & $(-2,02 ;-1,65)$ \\
\hline & Güvenli olduğu & $\underline{(10,25 ; 9,07)}$ & $(3,90 ; 2,72)$ & $(0,65 ;-0,52)$ & $(2,09 ; 0,91)$ \\
\hline & Bilgi sahibi olunması & $(8,67 ; 7,75)$ & $(2,33 ; 1,41)$ & $(-0,93 ;-1,84)$ & $(0,51 ;-0,49)$ \\
\hline
\end{tabular}

Altın yatırım aracı, gayrimenkul yatırım aracının tüm stratejilerine göre güvenli olduğu stratejisi daha baskın çıkmıştır. Gayrimenkul yatırım aracı, altın yatırım aracının tüm stratejilerine göre faiz oranı yüksek stratejisi daha baskın çıkmıştır. Dolaysıyla (faiz oranı yüksek, güvenli olduğu) hücresindeki $(10,25 ; 9,07)$ değeri oyunun baskın strateji dengesi olarak belirlenmiştir. Nash dengesi her iki oyuncu içinde kazançlı olduğundan, yatırım araçlarının faiz oranın yüksek olması ve güvenilir yatırım araçları stratejilerine göre Jenerasyon $\mathrm{Y}$ kuşağı üniversite öğrencilerinin gelecekte tercih etmeyi düşündükleri yatırım araçlarında beklentilerinin denge durumunu oluşturmaktadır.

Altın yatırım aracı, döviz yatırım aracının tüm stratejilerine göre güvenli olduğu stratejisi daha baskın çıkmıştır. Döviz yatırım aracının, altın yatırım aracının tüm stratejilerine göre faiz oranı yüksek stratejisi daha baskın çıkmıştır. Dolaysıyla (faiz oranı yüksek, güvenli olduğu) hücresindeki $(10,5 ; 9,60)$ değeri oyunun baskın strateji dengesi olarak belirlenmiştir.

Tablo 12. Altın ve Döviz Nash Dengesi

\begin{tabular}{|c|c|c|c|c|c|}
\hline \multirow{2}{*}{ OYUN 2} & \multicolumn{5}{|c|}{ Döviz (İkinci Oyuncu) } \\
\hline & Stratejiler & Faiz oranı yüksek & Yüksek kar getirisi & Güvenli olduğu & Bilgi sahibi olunması \\
\hline \multirow{4}{*}{ 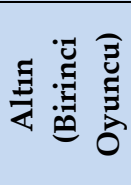 } & Faiz oranı yüksek & $(-0,65 ; 0,72)$ & $(-7,15 ;-5,78)$ & $(-10,75 ;-9,38)$ & $(-9,36 ;-7,99)$ \\
\hline & Yüksek kar getirisi & $(6,45 ; 6,56)$ & $(-0,06 ; 0,06)$ & $(-3,65 ;-3,53)$ & $(-2,26 ;-2,14)$ \\
\hline & Güvenli olduğu & $(10,5 ; 9,60)$ & $(4,04 ; 3,10)$ & $(0,44 ;-0,49)$ & $(1,83 ; 0,89)$ \\
\hline & Bilgi sahibi olunması & $(8,97 ; 8,42)$ & $(2,47 ; 1,92)$ & $(-1,12 ;-1,67)$ & $(0,26 ;-0,28)$ \\
\hline
\end{tabular}


Döviz yatırım aracı, gayrimenkul yatırım aracının tüm stratejilerine göre güvenli olduğu stratejisi daha baskın çıkmıştır. Gayrimenkul yatırım aracı, döviz yatırım aracının tüm stratejilerine göre faiz oranı yüksek stratejisi daha baskın çıkmıştır. Dolaysıyla (faiz oranı yüksek, güvenli olduğu) hücresindeki $(8,67 ; 8,45)$ değeri oyunun baskın strateji dengesi olarak belirlenmiştir.

Tablo 13. Gayrimenkul ve Döviz Nash Dengesi

\begin{tabular}{|c|l|c|c|c|c|}
\hline \multirow{2}{*}{ OYUN 3 } & \multicolumn{5}{|c|}{ Gayrimenkul yatırım (İkinci Oyuncu) } \\
\cline { 2 - 6 } & \multicolumn{1}{|c|}{ Stratejiler } & Faiz oranı yüksek & Yüksek kar getirisi & Güvenli olduğu & Bilgi sahibi olunması \\
\hline \multirow{3}{*}{$\left.* \begin{array}{c}* \\
:\end{array}\right)$} & Faiz oranı yüksek & $(-0,20 ; 0,14)$ & $(-5,99 ;-5,63)$ & $(-8,75 ;-8,39)$ & $(-7,49 ;-7,13)$ \\
\cline { 2 - 6 } & Yüksek kar getirisi & $(5,64 ; 5,88)$ & $(-0,14 ; 0,10)$ & $(-2,90 ;-2,65)$ & $(-1,64 ;-1,39)$ \\
\cline { 2 - 6 } & Güvenli olduğu & $\underline{(8,67 ; 8,45)}$ & $(2,89 ; 2,66)$ & $(0,13 ;-0,09)$ & $(1,39 ; 1,16)$ \\
\cline { 2 - 6 } & Bilgi sahibi olunması & $(7,49 ; 7,12)$ & $(1,71 ; 1,34)$ & $(-1,04 ;-1,41)$ & $(0,21 ;-0,15)$ \\
\hline
\end{tabular}

\section{SONUÇ}

Jenerasyon Y kuşağının gelecekte hangi tür yatırım aracını kullanacağını ve bu yatırım araçlarını tercih ederken hangi ölçütlere göre karar vereceğini belirlemek için oyun teorisi yaklaşımı kullanıldı. Kümele analizi yapılarak da Jenerasyon Y kuşağı öğrencilerinin yatırım hakkındaki eğilimleri tespit edilmiş oldu. Elde edilen sonuçlara göre, kümeleme analizinde 3 kümeye ayrıştıkları ve \%30'unu temsil eden 1 . kümede olan öğrencilerin yatırım aracı seçerken faizi istemedikleri fakat yatırım araçlarının güvenilir, yüksek kar getirisinin olması ve yatırım aracı hakkında bilgi sahibi olmasını istemektedirler. \%15'ini temsil eden 2. kümede ki öğrencilerin yatırıma pek eğilimlerinin olmadığ görülmektedir. \%55'ini temsil eden 3. kümede ise öğrencilerin yatırım konusunda eğilimli oldukları ve yatırım aracı seçerken tüm ölçeklerin dikkate alınması gerektiğini düşünmektedirler.

Oyun kuramı modelinde altın ve gayrimenkul sıfır toplamlı oyun probleminde altın yatırım aracının güvenli olduğu stratejisi, gayrimenkul yatırım aracının her stratejisinden daha kazançlıdır. Sıfır toplamlı olmayan oyun probleminde ise altın yatırım aracını tercih eden öğrencilerinin güvenli olduğu stratejisine verdikleri puanın, hedef kitlenin faiz oranı yüksek, yüksek kar getirisi ve bilgi sahibi olunması stratejilerine verdikleri puanlardan daha yüksek çıkmıştır. Gayrimenkul yatırım aracını tercih eden öğrencilerinin faiz oranı yüksek stratejisine verdikleri puanın, hedef kitlenin yüksek kar getirisi, güvenli olduğu ve bilgi sahibi olunması stratejilerine verdikleri puanlardan daha düşük çıkmıştır. Altın yatırım aracı, gayrimenkul yatırım aracının tüm stratejilerine göre güvenli olduğu stratejisi daha baskın çıkmıştır. Gayrimenkul yatırım aracı, altın yatırım aracının tüm stratejilerine göre faiz oranı yüksek stratejisi daha baskın çıkmıştır. Dolaysıyla $(10,25 ; 9,07)$ değeri oyunun baskın strateji dengesi olarak belirlenmiştir. Faiz oranın yüksek olması ve güvenilir yatırım araçları stratejilerine göre Jenerasyon $Y$ kuşağı üniversite öğrencilerinin gelecekte tercih etmeyi düşündükleri yatırım araçlarında beklentilerinin denge durumunu oluşturmaktadır.

Altın yatırım aracı, döviz yatırım aracının tüm stratejilerine göre güvenli olduğu stratejisi daha baskın çıkmıştır. Döviz yatırım aracının, altın yatırım aracının 
tüm stratejilerine göre faiz oranı yüksek stratejisi daha baskın çıkmıştır. $(10,5 ; 9,60)$ değeri oyunun baskın strateji dengesi olarak belirlenmiştir. Döviz yatırım aracı, gayrimenkul yatırım aracının tüm stratejilerine göre güvenli olduğu stratejisi daha baskın çıkmıştır. Gayrimenkul yatırım aracı, döviz yatırım aracının tüm stratejilerine göre faiz oranı yüksek stratejisi daha baskın çıkmıştır. $(8,67 ; 8,45)$ değeri oyunun baskın strateji dengesi olarak belirlenmiştir. Sonuç olarak Jenerasyon Y kuşağı öğrencilerinin gelecekte en güvenilir yatırım aracı olarak altını tercih edeceklerdir. Gayrimenkul yatırım aracını ise faiz oranı stratejisi bakımından altın ve döviz yatırım araçlarına göre daha baskın olarak tercih edeceklerdir.

Jenerasyon $\mathrm{Y}$ kuşağına yönelik yapılan yatırım kampanyalarında firmaların onların yatırım araçlarındaki beklentilerine yönelik olarak kampanyalar düzenlemesi daha yararlı sonuçlar alınacağı önerilmiştir. Özellikle altın yatırım aracına yönelik kampanyalarda güvenirlik ölçütüne vurgu yapılmasının onlar üzerinde daha fazla etki yapacağı sonucuna varılmıştır. Gayrimenkul yatırım ve döviz kampanyalarında ise faiz oranın yüksek olacağı ölçütüne vurgu yapılması gerektiği önerilmiştir.

\section{KAYNAKÇA}

Ayvaz, T. (2013) 'Y Kuşağı Özellikleri'. 15 Eylül 2016 tarihinde http://www.dijitalajanslar.com/ykusagi/ adresinden erişildi.

Bali, T. G., Demirtas, K. O., Levy, H. \& Wolf, A. (2009) 'Bonds versus stocks: Investors' age and risk taking', Journal of Monetary Economics, 56, 817-30.

Branchik, B. J. (2010) 'Silver dollars: The development of the US elderly market segment', Journal of Historical Research in Marketing, 2, 174-97.

Broadbridge, A. M., Maxwell, G. A. \& Ogden, S. M. (2007) '13_2_30: Experiences, perceptions and expectations of retail employment for Generation Y', Career Development International, 12, 523-44.

Bucuță, A. (2015) 'A Review of the Specific Characteristics of the Generation Y Consumer', Proceedings of the International Conference Marketing - from Information to Decision, 8, 38-47.

Chang, C.-H. (2008) 'The impact of behavioral pitfalls on investors decisions: the disposition effect in the Taiwanse warrant market', Social Behavior and Personality: an international journal, 36, 617-34.

Corter, J. E. \& Chen, Y.-J. (2006) 'Do investment risk tolerance attitudes predict portfolio risk?', Journal of Business and Psychology, 20, 369-81.

Bugaoglu, T. (2013) "Edalman'dan Y kuşağının gelecek analizi" 20 Ekim 2016 tarihinde http://www.halklailiskiler.com.tr/Edalmandan_Y_kusaginin_gelecek_analizi..php/ adresinden erişildi.

Eisner, S. P. (2005) 'Managing generation Y', SAM Advanced Management Journal, 70, 4.

Ferguson, E., Heckman, J. J. \& Corr, P. (2011) 'Personality and economics: Overview and proposed framework', Personality and Individual Differences, 51, 201-09.

Foreman, H. (2006) 'Understand gen Y employees', Credit Union Magazine, 72, 70-71. 
Francis-Smith, J. (2004) 'Surviving and thriving in the multigenerational workplace', Journal Record, 1,1 .

Ganesan, A. S. (2012) 'Consumption, spending and investment behaviour of malaysia generation $y^{\prime}$, UTAR.

Grable, J., Lytton, R. \& O'neill, B. (2004) 'Projection bias and financial risk tolerance', The Journal of Behavioral Finance, 5, 142-47.

Grable, J. E. (2000) 'Financial risk tolerance and additional factors that affect risk taking in everyday money matters', Journal of Business and Psychology, 14, 625-30.

Hallahan, T., Faff, R. \& Mckenzie, M. (2003) 'An exploratory investigation of the relation between risk tolerance scores and demographic characteristics', Journal of Multinational Financial Management, 13, 483-502.

Halstead, K. M. (2006) Socialization agents influencing Anglo and Hispanic American generation $\mathrm{Y}$ females' apparel consumption, University of North Carolina at Greensboro.

Howe, N. \& Strauss, W. (1992a) Generations: The history of America's future, 1584 to 2069, Harper Collins.

Howe, N. \& Strauss, W. (1992b) 'The new generation gap', ATLANTIC-BOSTON-, 270, 67-67.

Kennedy, L. (2001) 'The up \& coming generation', Retail Merchandiser, 41, 66.

Kim, H., Knight, D. K. \& Crutsinger, C. (2009) 'Generation Y employees' retail work experience: The mediating effect of job characteristics', Journal of Business Research, 62, 548-56.

Kotler, P. \& Armstrong, G. (2010) Principles of marketing, pearson education.

Martin, C. A. (2005) 'From high maintenance to high productivity: What managers need to know about Generation Y', Industrial and commercial training, 37, 39-44.

Maxfield, S., Shapiro, M., Gupta, V. \& Hass, S. (2010) 'Gender and risk: women, risk taking and risk aversion', Gender in Management: An International Journal, 25, 586-604.

Mcewan, A. M. (2009) 'Generation Y: coming to a workplace near you', The Smart Work Company Ltd., London, UK.

MFS (2011) 'MFS Investing Sentiment Survey: Shift to Cash is Deliberate, Fundamental Change for Investors'. 15 Eylül 2016 tarihinde http://www.businesswire.com adresinden erişildi.

Mishra, S., Lalumière, M. L. \& Williams, R. J. (2010) 'Gambling as a form of risk-taking: Individual differences in personality, risk-accepting attitudes, and behavioral preferences for risk', Personality and Individual Differences, 49, 616-21.

Mitchell, B. (2005) 'Understanding and Managing Different Generations', Achieve Solutions.

Morton, L. P. (2002) 'Targeting generation Y', Public Relations Quarterly, 47, 46.

Nash, J. (1951) 'Non-cooperative games', Annals of mathematics, 286-95.

Noble, S. M., Haytko, D. L. \& Phillips, J. (2009) 'What drives college-age Generation Y consumers?', Journal of business research, 62, 617-28.

Peters, H. (2015) Game theory: A Multi-leveled approach, Springer. 
Sadi, R., Asl, H. G., Rostami, M. R., Gholipour, A. \& Gholipour, F. (2011) 'Behavioral finance: The explanation of investors' personality and perceptual biases effects on financial decisions', International journal of economics and finance, 3, 234.

Salahuddin, M. M. (2010) 'Generational differences impact on leadership style and organizational success', Journal of Diversity Management, 5, 1.

Shiller, R. J. (2003) 'From efficient markets theory to behavioral finance', The Journal of Economic Perspectives, 17, 83-104.

Simon, H. A. (1987) 'Making management decisions: The role of intuition and emotion', The Academy of Management Executive (1987-1989), 57-64.

Tolbize, A. (2008) 'Generational differences in the workplace', Research and training center of community living, 19, 1-13.

John A. (2011) 'Generations: Key drivers of investor behavior', 20 Ekim 2016 tarihinde https://institutional.vanguard.com/iam/pdf/TRFTLC.pdf adresinden erişildi.

Wang, A. (2011) 'Younger Generations' Investing Behaviors in Mutual Funds: Does Gender Matter?', The Journal of Wealth Management, 13, 13.

Williams, K. C. \& Page, R. A. (2011) 'Marketing to the generations', Journal of Behavioral Studies in Business, 3, 1 .

Winston, W. L. \& Goldberg, J. B. (2004) Operations research: applications and algorithms, Duxbury press Boston.

Young, S., Gudjonsson, G. H., Carter, P., Terry, R. \& Morris, R. (2012) 'Simulation of risk-taking and it relationship with personality', Personality and Individual Differences, 53, 294-99. 